\title{
GOVERNANÇA CORPORATIVA COMO ELEMENTO DE COMPETITIVIDẢDE GLOBAL: ANÁLISE DA PERCEPÇÃO DOS GESTORES DE EMPRESAS EXPORTADORAS DE CAXIAS DO SUL
}

\section{CORPORATE GOVERNANCE AS A GLOBAL COMPETITIVINESS ELEMENT: AN ANALISYS OF THE PERCEPTION OF EXPORTING COMPANIES MANAGERS FROM CAXIAS DO SUL}

\author{
Camila Ploia Haas Manera ${ }^{1}$; Guilherme Bergmann Borges Vieira ${ }^{2}$ \\ ${ }^{1}$ Autarquia Municipal de Turismo Gramadotur - Gramado - RS - Brasil \\ ploiahaas@gmail.com \\ ${ }^{2}$ Universidade de Caxias do Sul - UCS - Caxias do Sul - RS - Brasil \\ gbbvieir@ucs.br
}

\begin{abstract}
Resumo
Este estudo tem como objetivo analisar a percepção dos gestores de empresas exportadoras de Caxias do Sul sobre a governança corporativa como fator de competitividade global. $O$ método utilizado foi qualitativo de caráter exploratório. Os dados foram coletados através de um roteiro semiestruturado de questões e analisados destacando os principais benefícios e dificuldades de implementação das práticas de governança corporativa nas empresas estudadas, bem como o grau de consenso e divergência dos gestores sobre as práticas de governança como fator de competitividade global. Os resultados indicam que os gestores percebem a importância da adoção das práticas de governança corporativa para a perpetuação das organizações em mercado de capitais, embora na relação com os clientes esse aspecto não seja considerado importante. Conforme a literatura da área, a pesquisa também revelou a importância de aspectos comportamentais associados à governança, tais como mudança de mentalidade, quebra de paradigmas e choque cultural.
\end{abstract}

Palavras-chave: governança corporativa; competitividade global; percepção dos gestores; empresas exportadoras; caxias do sul.

\section{Introdução}

No início dos anos 90, devido a conflitos de interesse e condutas abusivas por parte de alguns executivos, nasceu a governança corporativa, que vem ao encontro da necessidade crescente das organizações de criarem práticas para reger suas operações com base em diretrizes mais claras de gestão. Associado a ela está o conjunto de boas práticas que tem como papel principal garantir retorno ao investidor (IBGC, 2009). A governança corporativa é um sistema que estrutura as organizações no que diz respeito à tomada de decisões estratégicas e ao exercício de liderança, e que trata da administração da separação entre gestão e propriedade (ANDRADE; ROSSETTI, 2004). 
Segundo Berle e Means (1984), o modelo adotado até o início da Revolução Industrial propriedade-gestão - não se mostrou adequado ao processo de mudança que começava a se desenhar em meados dos anos 30. Após esse período, os administradores das empresas deixaram de ser necessariamente seus proprietários e, com isso, passou a haver uma separação entre propriedade e gestão, surgindo os preceitos de governança corporativa (MONKS; MINOW, 1995).

A governança corporativa geralmente é exposta na literatura sob um ponto de vista específico, que diz respeito aos resultados das operações e à relação com investidores. Porém, alguns autores começam a tratar o tema também em sua dimensão humana. Steinberg (2003), por exemplo, dá um novo enfoque à governança corporativa. Conforme o autor é errôneo pensar que somente seguir regulamentos seria praticar a boa governança. Segundo Steinberg (2003), a governança corporativa se relaciona diretamente com a atitude e a escala de valores humanos. Então, pode-se dizer que praticar boa governança é alinhar os pensamentos dos diversos atores presentes nas organizações (acionistas, controladores e stakeholders).

De acordo com essa ideia, Peters (2007), em texto sobre implementação e gerenciamento da lei SOX, ressalta a relevância dos valores éticos para a perpetuação de uma organização. Peters (2007) defende que é necessária a disseminação dos valores e da cultura de controle dentro da organização, já que os mesmos definem o comportamento e o comprometimento dos colaboradores perante a empresa. Peters (2007) afirma que não é suficiente o cumprimento das leis vigentes, pois um sistema de controle não pode ser eficaz se estiver acima da moral e integridade das pessoas que o administram e supervisionam, uma vez que são os valores que dão suporte à estrutura dos controles.

Pesquisas sobre o tema, como a de Sandes (2012), expõem empiricamente o resultado da implantação das práticas, porém não abordam como os gestores percebem essas práticas e como avaliam o desempenho das companhias após a implantação das mesmas. Esse ponto pode ser crucial quanto ao entendimento do sucesso ou fracasso das implementações, já que a prática de governança, em seu sentido mais amplo, visa alinhar o pensamento de todos os atores (STEINBERG, 2003) e conciliar permanentemente conflitos (ANDRADE; ROSSETTI, 2004).

Ainda no âmbito comportamental da governança corporativa, Ribeiro et al. (2010) citam a necessidade de a mesma ser tratada em seus diversos âmbitos, seja na perspectiva financeira, de normas e regulamentos, como na perspectiva dos recursos humanos. Segundo os autores, uma vez contemplada essa dimensão, haverá a possibilidade de estabelecimento de políticas de treinamento, foco em aspectos comportamentais relacionados à confiança, ética entre funcionários, cultura organizacional, liderança e responsabilidade social, consolidando uma imagem de empresa que pratica governança corporativa integrada. 
Dado esse contexto, o presente estudo tem como objetivo analisar a percepção dos gestores de empresas exportadoras de Caxias do Sul sobre práticas de governança corporativa, principalmente quanto à relação entre tais práticas e a competitividade global; aos benefícios e dificuldades percebidos; às práticas que não puderam ser internalizadas; e aos motivos pelos quais as mesmas não foram implementadas. $\mathrm{O}$ estudo permite identificar os percalços que as empresas estudadas enfrentaram para por em prática as normas de governança corporativa e os principais frutos desse trabalho, tendo como foco a percepção de profissionais de gerência, buscando analisar o ponto de vista de quem administra.

\section{Referencial Teórico}

Neste capítulo são apresentados os principais conceitos associados à governança corporativa. Além disso, são destacadas algumas características do seu desenvolvimento no Brasil e no mundo.

\subsection{Conceitos de Governança Corporativa}

Por se tratar de uma temática relativamente nova e abrangente, não existe uma definição fechada sobre a governança corporativa e, na literatura, podem ser encontrados diferentes conceitos que derivam dos diferentes enfoques que o tema pode ter. Para o desenvolvimento do presente estudo, foram tomadas como base, em um primeiro momento, as definições que tratam mais especificamente da normativa dos processos de gestão e, posteriormente, foram analisados conceitos que contemplam a dimensão humana da temática e que relacionam a governança corporativa com a competitividade global das empresas.

Embora as definições possam variar de acordo com especificidades culturais, legais e econômicas (BABIC, 2003), quatro conceitos são unanimidade no que diz respeito à implementação da governança corporativa. São eles: Fairness (senso de justiça); disclosure (transparência); accountability (prestação responsável de contas); ecompliance (conformidade legal).

Sob a definição de Blair (1999), a governança corporativa é considerada uma forma de as corporações estabelecerem processos que ajustem possíveis conflitos de interesse entre dirigentes e acionistas. Embora abrangente, essa definição apresenta um dos pontos de onde surgiu a necessidade da normatização das práticas gerenciais. Evitar o conflito de agência é ponto fundamental e recorrente nas publicações sobre governança corporativa.

Ainda na mesma linha, tem-se o conceito de governança corporativa segundo a Organização para Cooperação e Desenvolvimento Econômico (OCDE, 2001), que a define como um sistema que controla e dirige as organizações. Nesse sistema, são especificados os direitos de cada uma das 
partes da corporação, bem como as normas e procedimentos utilizados nos processos de tomada de decisão corporativa.

Williamson (1996), por sua vez, mais voltado a um sistema de valores, define a governança corporativa como um sistema que observa a transparência, a justiça e a responsabilidade das empresas no que diz respeito aos interesses do negócio e da sociedade como um todo.

\subsection{Consolidação da Governança Corporativa através da Lei Sarbanes-Oxley}

A importância da gestão dentro de um sistema de governança corporativa é amplamente reconhecida, tanto que em 2002 surgiu um novo capítulo no desenvolver do tema: foi promulgada nos Estados Unidos a Lei Sarbanes-Oxley, ou SOX, que fez dos princípios de governança corporativa, que até então eram um conjunto normativo, uma lei.

Isso ocorreu em um contexto em que organizações de grande porte vinham sendo o centro de diversos escândalos corporativos, o que motivou a consolidação de fortes medidas regulatórias. Ou seja, a aplicação de controles internos nas corporações tornou-se uma necessidade, já que a confiança no mercado estava abalada devido às diversas ocorrências de fraudes (PETERS, 2007). Embora já existissem ao redor do globo diversos institutos que tratavam da aplicação das boas práticas de governança, isso não foi o suficiente para refrear práticas fraudulentas e condutas antiéticas em grandes organizações. Como exemplos, podem ser citados os casos de fraude na Enron, na WorldCom e na Tyco, o que acabou culminando na promulgação da SOX.

A SOX é baseada nos quatro pilares da governança corporativa: conformidade legal (compliance); prestação responsável de contas (accountability); transparência (disclosure); e senso de justiça (fairness). Esses pilares já haviam sido desenvolvidos anos antes e foram reafirmados na lei (ANDRADE; ROSSETTI, 2004). A SOX se aplica a empresas norte-americanas, multinacionais que tenham contato com o mercado de capitais norte-americano, ou subsidiárias de empresas norteamericanas. Para melhor entendimento de como as premissas da SOX contemplam os pilares da governança corporativa (GC), a Figura 1 apresenta algumas das mais expressivas normas da SOX relacionadas com as premissas de GC. 
Figura 1 - Normas da SOX relacionadas com os pilares de Governança Corporativa

\begin{tabular}{|c|c|}
\hline egal (Compliance) & re) \\
\hline $\begin{array}{l}\text { Para os principais executivos das corporações é } \\
\text { especificado um código de conduta que norteia a tomada } \\
\text { de decisões em questões como a divulgação de } \\
\text { informações, cumprimento de leis e questões em que } \\
\text { haja conflitos de interesse. } \\
\text { As corporações que não adotarem esse código deverão } \\
\text { prestar explicações sobre a não adoção àSecurity } \\
\text { Exchange Commission (SEC), órgão regulador norte- } \\
\text { americano equivalente à CVM. } \\
\text { No caso de adoção de código de ética, a SEC deverá } \\
\text { receber cópia e sua divulgação deverá ser aberta. }\end{array}$ & $\begin{array}{l}\text { Aqueles que detêm informações privilegiadas deverão } \\
\text { seguir as normas da lei para qualquer mudança em suas } \\
\text { participações acionárias. } \\
\text { A divulgação de informações complementares aos } \\
\text { relatórios exigidos e as contingências não incluídas no } \\
\text { balanço patrimonial deverão ser feitas com rapidez. } \\
\text { A SEC pode exigir a divulgação de informações não } \\
\text { contempladas no balanço patrimonial se julgar que estas } \\
\text { impactam nos resultados corporativos ou negócios da } \\
\text { companhia. }\end{array}$ \\
\hline Prestação de contas (Accountability) & Sen \\
\hline $\begin{array}{l}\text { O CEOs e CFOs são responsáveis: } \\
\text { a) pela apuração da veracidade de relatórios } \\
\text { divulgados e de que informações financeiras } \\
\text { reflitam exatamente o estado da companhia, } \\
\text { além de se certificar de que estes não omitam } \\
\text { informações relevantes; } \\
\text { b) porestabelecer controles internos, avaliar e } \\
\text { monitorar sua eficácia e, no caso de falhas ou } \\
\text { fraudes encontradas, divulgá-las aos auditores. }\end{array}$ & $\begin{array}{l}\text { A remuneração do executivo principal deverá ser } \\
\text { aprovada pelo Conselho de Administração. } \\
\text { Proibição de empréstimos pessoais a diretores e } \\
\text { executivos. } \\
\text { Em caso de fraude corporativa (alteração, ocultação, } \\
\text { falsificação de informações ou documentos com a } \\
\text { intenção de ocultar ou direcionar a análise do desempenho } \\
\text { e a situação dos negócios ou gestão) os responsáveis serão } \\
\text { passíveis de punição mediante multa ou prisão. }\end{array}$ \\
\hline $\begin{array}{l}\text { Além disso, é necessário o estabelecimento de um } \\
\text { Comitê de Auditoria que acompanhe os auditores, } \\
\text { verificando sua atuação. }\end{array}$ & $\begin{array}{l}\text { No caso de correção das demonstrações financeiras } \\
\text { causadas por descumprimento das normas estabelecidas } \\
\text { pela SEC, haverá devolução de bônus e lucros } \\
\text { distribuídos. }\end{array}$ \\
\hline
\end{tabular}

Fonte: Elaborado pelos autores com base em Andrade e Rossetti (2004) e Peters (2007)

As normas propostas pela SOX têm inspirado mudanças em outros países. No Brasil, já existem companhias que se adequaram a essas normas, o que leva a crer que já não existam grandes mudanças a serem feitas na forma como é organizado o mercado brasileiro para a adequação a normas que exijam padrões de conduta superiores, de acordo com pesquisa de Lemes e Santos (2004).

\subsection{Governança Corporativa no cenário brasileiro}

A necessidade de adequação às práticas de boa governança corporativa por parte das empresas brasileiras começou a surgir, primeiramente, como alinhamento às novas exigências dos mercados internacionais. A partir dos anos 90, com a maior abertura de mercado e a maior dificuldade de obtenção de financiamentos estatais, as companhias nacionais sentiram a necessidade de captação de recursos no mercado externo (SILVEIRA, 2002). Essa necessidade de captação a menor custo, juntamente com a atuação em mercados de capitais internacionais e a entrada de investidores estrangeiros no mercado de capitais nacional, levaram as empresas a se adequarem às novas exigências do mercado globalizado. Frente a isso, as empresas tiveram de rever o modelo de governança até então adotado, principalmente no que diz respeito à transparência de informações 
divulgadas ao mercado, direitos dos acionistas minoritários e profissionalização dos Conselhos de Administração (SILVEIRA, 2002).

Em 2001, trabalhos desenvolvidos pela Kinsey\&Company e Korn/Ferry Internacionale,posteriormente, analisados no estudo de Silveira (2002), traçaram um modelo geral de governança corporativa nas empresas brasileiras. Os referidos estudos encontraram as seguintes características nas empresas listadas na bolsa: i) estrutura de propriedade com forte concentração das ações com direito a voto (ordinárias) e alto índice de emissão de ações sem direito a voto (preferenciais);ii) falta de profissionalização dos Conselhos de Administração;iii) acionistas minoritários pouco ativos;iv) alta sobreposição entre propriedade e gestão, com os membros do conselho representando os interesses dos acionistas controladores; v) pouca clareza na divisão dos papéis entre Conselho e Diretoria, principalmente nas empresas familiares; vi) remuneração dos conselheiros considerada pouco relevante; e vii) estrutura informal do Conselho de Administração, com ausência de comitês para tratamento de questões específicas, como auditoria ou sucessão.

Com o objetivo de direcionar as companhias nacionais a um formato de gestão mais competitivo globalmente, algumas iniciativas institucionais e governamentais são identificadas em pesquisas como as de Silveira (2002), Vieira e Corrêa (2002) e Rogers (2006). Entre tais iniciativas, podem-se citar: i) distinção das empresas de acordo com seu nível de governança corporativa na BM\&F/Bovespa; ii) criação do código de boas práticas de Governança Corporativa da CVM;iii) criação do Instituto Brasileiro de Governança Corporativa em 1995, para tratar exclusivamente sobre o tema governança, lançando em 1999 o primeiro código de governança corporativa; e iv) aprovação da Lei $n^{\circ} 10.303$ de 31 de outubro de 2001, a Nova Lei das S/As.

A valorização da adoção das boas práticas nas empresas também é bem vista por parte de instituições governamentais. Como exemplo, pode-se citar o BNDES, que concede financiamentos com juros mais baixos a empresas que tiverem adotado boas práticas de governança corporativa, levando em conta que estas estão expostas a menos riscos (VIEIRA; CORRÊA, 2002).

Um fator importante para o desenvolvimento da governança corporativa em âmbito nacional foi a aprovação da Nova Lei das Sociedades Anônimas, em 2001, com alteração em 2008. A alteração, conforme resumo de Justen Filho (2008), diz respeito a três principais pontos: i) atualizar a Lei Societária de 1976; ii) adequar a Lei às mudanças sociais e econômicas que surgiram com a evolução do mercado; e iii) fortalecer o mercado de capitais ao aplicar normas contábeis e de auditoria.

Após a promulgação da SOX, que teve reflexos nas empresas brasileiras que mantinham negociações no mercado de capitais norte-americano, a BM\&F/Bovespa, alinhando-se às tendências mundiais, elaborou uma separação das empresas listadas em bolsa, de acordo com seu nível de 
governança corporativa, criando quatro níveis distintos na listagem do mercado de ações: Novo Mercado; Nível 2; Nível 1 e Bovespa Mais (BARROS, 2002).

O objetivo da distinção, de acordo com Barros (2002), deve-se à utilização da governança corporativa como instrumento para o desenvolvimento do mercado de capitais brasileiro, já que ela fornece a segurança necessária aos investidores e valoriza as empresas que adotam boas práticas, promovendo um custo de captação menor. Embora a implementação de práticas de governança corporativa não exclua completamente a possibilidade de prejuízo no mercado, ela atua como uma importante ferramenta que garante diversos direitos aos acionistas. Mesmo não sendo garantia de valorização permanente dos papéis, as práticas exigem que sejam expostas mais informações, possibilitando aos investidores uma avaliação mais segura sobre a situação da empresa no momento da escolha da carteira de ações.

O Novo Mercado conta com regras mais rígidas de governança corporativa. A tendência é de que as empresas listadas nele sejam mais atraentes a investidores, devido ao fato de seguirem regras reconhecidas internacionalmente e estarem sujeitas a controles internos mais rígidos.

Para verificar e comparar o desempenho de empresas que adotam práticas de governança corporativa superiores em relação às que não o fazem, foi criado o Índice de Ações com Governança Corporativa Diferenciada (IGC). Esse índice é calculado desde julho de 2001 e tem como finalidade verificar o desempenho no mercado nacional de uma carteira teórica composta por empresas que figuram nos níveis mais altos de governança em comparação ao IBOVESPA. Basicamente, são avaliados, comparativamente ao índice Bovespa, quatro aspectos: retorno, liquidez, custo de captação e risco. Recentemente, Sandes (2012), em artigo comparando o desempenho de ações de empresas do IGC ao IBOVESPA, em um determinado período de tempo, chegou ao resultado de que o IGC gerou retorno superior ao IBOVESPA. Similarmente ao exposto por Sandes (2012), em pesquisa realizada pela McKinsey Company (MCKINSEY, 2000), foi constatado em entrevistas com investidores da Europa, Ásia e América Latina que 80\% deles estavam dispostos a pagar mais por uma empresa que adotasse práticas de boa governança. Além disso, $75 \%$ afirmaram considerar a governança tão importante quanto o desempenho financeiro da companhia.

\subsection{Governança Corporativa e competitividade global}

Conforme Porter (2003), é rara a ocorrência de uma indústria que seja global desde seu início, mas existe a tendência de muitas se tornarem globais com o passar do tempo. Logo, para muitas empresas, o caminho natural de expansão de suas atividades é o mercado internacional, seja em transações de compra e venda ou mediante a participação em mercados de capitais internacionais. 
Andrade e Rossetti (2004) explicam que, no âmbito internacional, existem agentes que sustentam a tendência à adoção das boas práticas de governança corporativa. Entre esses agentes, podem-se citar os próprios investidores que, conforme a pesquisa realizada pela McKinsey Company (2000) anteriormente citada, em mercados internacionais dão grande valor às companhias que adotam boas práticas de governança corporativa.

Conforme pesquisa da McKinsey Company (2000), a governança corporativa compõe o conjunto de fatores críticos analisados pelos investidores em mercados internacionais. Além disso, existe uma classificação corporativa reconhecida internacionalmente por potenciais emprestadores de recursos e investidores, os chamados ratings, que medem as empresas quanto a sua capacidade de pagamento futuro (FRAZÃO, 2005). Essa classificação inclui uma série de fatores, dentre eles o nível de governança corporativa adotado pela companhia em questão.

Conforme explicado por Frazão (2005), um rating é composto por análises qualitativas, quantitativas e jurídicas. Vale observar que a governança corporativa não é fator isolado na avaliação de uma empresa, mas, como citado por Frazão (2005), a governança é analisada para compor o rating e é um fator importante para a atração de investidores.

No âmbito internacional, em relatório oficial sobre governança corporativa na América Latina, a OCDE (2003) expõe que a boa governança é fundamental ao crescimento econômico do setor privado na região. O relatório menciona que, para serem competitivas internacionalmente, as empresas latino-americanas devem ser capazes de adaptar as boas práticas administrativas e de governança ao contexto local.

Sobre competição global, o relatório expõe que "os efeitos da internacionalização dos mercados sobre a organização industrial transfronteira ainda estão sendo sentidos em termos de eliminação de concorrentes." (OCDE, 2003, p. 10). Efeitos dessa tendência de adequação global às normas de governança incluem a saída de empresas do mercado de valores mobiliários internacional e, no caso das subsidiárias de multinacionais, a adequação às normas da SOX e aos modelos de governança vigentes no país da matriz (ODCE, 2003).

\section{Procedimentos Metodológicos}

Para investigar a percepção dos gestores sobre a governança corporativa, esta pesquisa valeu-se de uma abordagem qualitativa de caráter exploratório. Selltiz (apud FIGUEIREDO, 2004) refere-se à pesquisa exploratória como uma modalidade de pesquisa que realiza coleta de dados em amostras pequenas através de entrevistas com pessoas com experiência prática no objeto da pesquisa.

No caso do presente estudo, foram selecionadas empresas exportadoras localizadas em Caxias do Sul e foram entrevistados quatro gestores, identificados como A, B, C e D. Os 
profissionais entrevistados compõem a alta gerência nas áreas de tecnologia da informação, finanças, controladoria e comércio exterior. Cabe salientar que as três primeiras áreas são as que comumente têm controles de governança mais rígidos e a última proporciona uma boa perspectiva sobre competitividade global. Foram selecionados entrevistados que tivessem conhecimento de práticas de governança corporativa por estarem atuando em empresas que atendessem às exigências de governança ou por experiências profissionais prévias, uma vez que a pesquisa foi direcionada à análise da opinião dos gestores e não à visão da corporação.

A amostra de empresas participantes mostrou-se variada e cada empresa, segundo seu perfil, tendo implementado práticas de governança ou não, forneceu um prisma de observação relevante. A empresa em que atuam os gestores A e B, por exemplo, serve como caso de referência por ser uma empresa de capital aberto e já adotar práticas de GC. Por esse motivo, foram realizadas duas entrevistas nessa empresa, com gestores das áreas de controladoria e de comércio exterior.

Os outros dois casos são exemplos de como os gestores de empresas de diferentes estruturas percebem as normas de GC. O gestor $\mathrm{C}$ atua em uma filial de um grupo norte-americano. Esse profissional foi selecionado por ter conduzido recentemente adequações às exigências da SOX, acompanhando as diretrizes da matriz. E o gestor D gerencia a área financeira de uma filial de um grupo holandês que atua no mercado externo desde a sua fundação. Este gestor foi selecionado por estar inserido em uma empresa com atuação internacional, o que auxilia a obter uma perspectiva sobre a questão da competitividade global. Sendo assim, os gestores C e D provem uma perspectiva de comparação com o caso da empresa em que atuam os gestores A e B, que é o tipo de empresa mais comumente estudado.

As entrevistas foram conduzidas por meio de um roteiro de questões semiestruturado e foram gravadas em meio digital. O roteiro de questões foi elaborado com base na revisão da literatura, respeitando os objetivos propostos para responder ao problema de pesquisa.

Após sua realização, as entrevistas forma transcritas e submetidas a procedimentos de análise de conteúdo (BARDIN, 2000; BAUER; GASKELL, 2002). Os relatos foram analisados primeiramente confrontando as percepções dos entrevistados com o referencial teórico identificado em cada um dos quatro pontos a seguir: i) motivos para adoção de práticas de GC; ii) benefícios percebidos; iii) dificuldades percebidas; e iv) não implementação de práticas (fatores impeditivos). A seguir, foi feita uma análise comparativa que explicitou os pontos de concordância ou divergência percebidos pelos gestores das empresas, a fim de traçar a percepção dos dirigentes de empresas de Caxias do Sul em relação à governança corporativa como fator diferencial em competitividade global.A Figura 2 apresenta resumidamente o processo descrito de análise de dados para a resolução do problema de pesquisa. 
Figura 2 - Síntese dos procedimentos para análise de dados

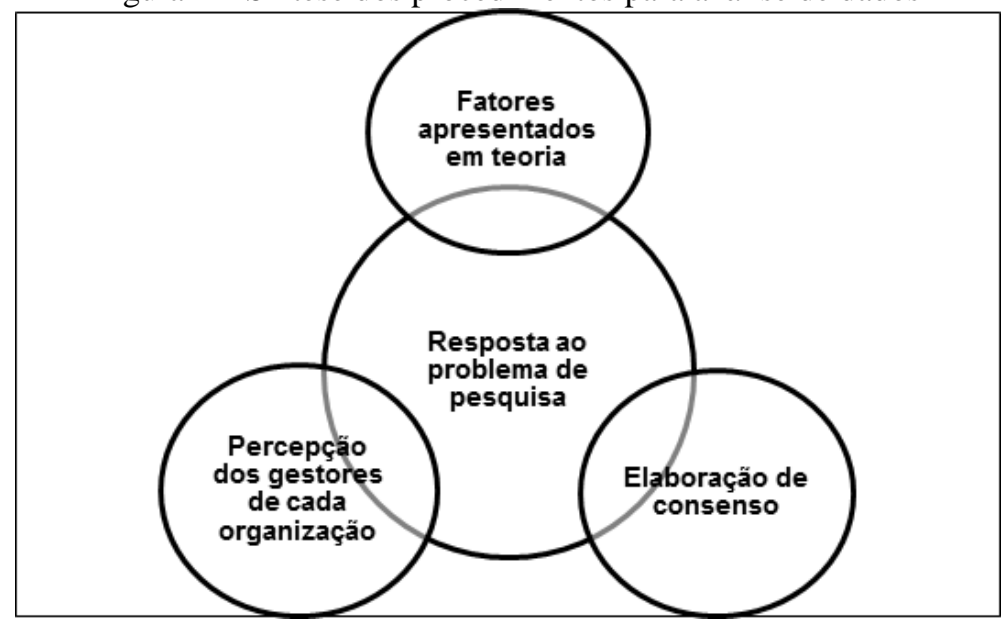

Fonte: Elaborado pelos autores

Conforme a Figura 2, a resposta ao problema de pesquisa decorre da análise dos fatores presentes na literatura, juntamente com as percepções dos gestores, identificadas após as análises das entrevistas individuais em profundidade, e a elaboração de consenso pela análise do conjunto de entrevistas realizadas.

\section{Resultados}

Nesta seção são apresentados os resultados da pesquisa. Para tanto, inicialmente é apresentada a descrição das entrevistas e, a seguir, é exposta a síntese dos resultados. A descrição das entrevistas é feita separadamente para cada gestor entrevistado (A, B, C e D). Já a síntese dos resultados apresenta de forma consolidada a percepção dos entrevistados quanto às dificuldades da implantação de práticas de governança corporativa, aos benefícios de sua internalização e a sua relação com a competitividade global.

\subsection{Descrição das entrevistas}

A descrição das entrevistas é feita separadamente por gestor, uma vez que o foco da pesquisa está em identificar a percepção dos gestores da região, independentemente das empresas em que atuam. Na sequência, é apresentada a descrição das entrevistas realizadas.

\section{Gestor A}

Conforme o Gestor A, as principais dificuldades encontradas em um processo de implementação de boas práticas de governança corporativa são comportamentais, principalmente no que diz respeito à mudança de cultura e de paradigmas em relação a práticas comuns. O Gestor $\mathrm{A}$ citou que, muitas vezes, a implementação de controles mais severos traz desconforto aos gestores, uma vez que estes começam a fazer parte de um sistema mais controlado e que pode ser 
interpretado, em um primeiro momento, como perda de autonomia. Por isso, o entrevistado ressaltou que essas práticas devem ser implementadas de forma gradual, a fim de não causar maior estresse.

Além disso, outra tarefa desafiadora para as empresas é adequar seus sistemas de informação às exigências dos controles de governança corporativa que visam preservar a transparência e a rastreabilidade de dados e informações. Esse ponto foi percebido como dificuldade pelas demasiadas exigências e pelos altos custos gerados para a adequação dos sistemas de informação. Outro obstáculo enfrentado pelas empresas é sua própria estrutura.

Nesse sentido, o Gestor A afirmou que as empresas muitas vezes se estruturam de forma diferente do que exigem as normas de GC, o que, segundo o gestor, traz dificuldades no momento de redistribuição de cargos e tarefas, especialmente em empresas que nasceram e perpetuaram como estruturas familiares. Nesse ponto, o gestor comentou também que não acredita que seja amplamente possível a implementação das práticas de governança em empresas de menor porte, já que a estrutura dessas empresas é enxuta e, muitas vezes, o mesmo profissional exerce tarefas que as normas exigem que sejam efetuadas por cargos distintos.

Um ponto interessante destacado pelo Gestor A, visto em uma segunda fase de implementação das práticas de GC, é que, após essa primeira fase de desconforto e mudanças geradas pela internalização de novos controles, os gestores começam a perceber o benefício das mudanças, principalmente no que diz respeito ao compartilhamento de riscos e decisões, o que, segundo ele, é uma forma de proteção ao gestor. Ainda no campo dos benefícios, corroborando um fator citado na literatura, foi destacada a atração de novos investidores, uma vez que o mercado tende a confiar mais em empresas que atendam às exigências de GC.

No que diz respeito à governança corporativa em relação ao mercado externo, o Gestor A afirmou que, de acordo com sua experiência, essa é uma relação complexa de se estabelecer. O entrevistado afirmou perceber claramente o valor que investidores e o mercado de capitais dão a empresas que buscam se adequar às práticas de GC. Porém, não acredita que o cliente no mercado externo perceba isso como ponto diferencial. O gestor destaca que o mercado externo é muito suscetível à escolha por preços e qualidade.

\section{Gestor B}

O Gestor $\mathrm{B}$ atua na mesma empresa que o Gestor $\mathrm{A}$, porém na área de comércio internacional. Seguem os principais pontos destacados da entrevista.

O Gestor B citou como motivo para a adoção das práticas a abertura de capital da empresa. Nesse processo, as dificuldades percebidas pelo Gestor B são mais voltadas à adequação da divulgação de informações e da comunicação com os investidores. O entrevistado comentou que 
vários processos passaram por padronização e adequação para atender às exigências. A forma como as informações eram divulgadas passou por mudança, já que a empresa tem de garantir ao mercado a transparência em relação a tudo o que se passa na organização.

O Gestor B também citou isso como uma dificuldade, uma vez que todos os envolvidos devem estar sensibilizados da importância da implementação das práticas de governança. Nesse ponto, ele ressaltou que a comunicação e o comprometimento de todos é fundamental para o sucesso do funcionamento das referidas práticas. É ponto convergente das opiniões dos gestores A e B que os aspectos comportamentais afetam a forma como as práticas são internalizadas. É crucial que esse ponto seja devidamente observado, uma vez que, conforme definição de Steinberg (2003), as práticas de governança devem alinhar o pensamento de todos os atores.

Com relação aos benefícios percebidos, o Gestor B citou como exemplo majoritário em sua percepção a confiança que a adequação às práticas de governança gera aos investidores. $\mathrm{O}$ entrevistado afirmou que a transparência e os controles exigidos fazem com que a empresa seja mais bem vista e valorizada no mercado. O gestor B mencionou ainda que essas práticas respaldam o crescimento sustentável da organização. Esse também é um ponto de concordância nas entrevistas dos gestores A e B.

Em relação ao mercado externo, o Gestor B não vê a internalização das práticas como fator influenciador para o cliente, mas sim com relação à competitividade e crescimento no mercado de capitais. Segundo o entrevistado, essas práticas são muito bem vistas pelos investidores e pelo mercado, mas dificilmente percebidas pelos clientes.

\section{Gestor C}

A opinião de um profissional que atua em uma empresa que difere da natureza majoritária de empresas que adotam boas práticas de GC (empresas de capital aberto) exemplifica de forma diferente a implementação de práticas de governança corporativa. Neste caso, foi entrevistado um executivo responsável por conduzir a implantação das normas SOX na área de tecnologia da informação de uma filial de um grupo norte-americano.

Mais uma vez, a aceitação e adequação a uma nova forma de trabalho foi relatada como uma dificuldade. $\mathrm{O}$ choque de culturas ocasionado pela adequação às práticas adotadas pela matriz foi um dos percalços encontrados no processo. Outro ponto interessante a se destacar é a dificuldade de conscientização dos atores, que em primeiro momento perceberam as práticas como algo meramente burocrático.

O Gestor C relatou que as diversas exigências da SOX criaram uma demanda por serviços específicos e que a região não dispunha de fornecedores que suprissem essa demanda por completo. A dificuldade de prospecção e desenvolvimento de fornecedores que atendessem a demandas 
específicas é um ponto relevante, que mostra que as empresas muitas vezes não contam com o suporte necessário em suas cadeias de suprimentos. Isso ocorre por se tratar de exigências relativamente novas, que diferem dos controles adotados até então no mercado interno.

A despeito das dificuldades, o Gestor $\mathrm{C}$ citou que, após a internalização das práticas, os benefícios foram notáveis no que diz respeito ao controle de dados e ao delineamento de atribuições, embora no início do processo houvesse resistência por parte de gestores e colaboradores. Outro ponto citado, que converge com a opinião do Gestor A, é que, com os procedimentos implementados, os gestores passaram a contar com maior proteção, uma vez que o risco passou a ser compartilhado.

Além disso, houve descentralização do conhecimento e maior proteção de dados. O que fica claro nesta entrevista é que a SOX, como parte da GC, no âmbito da tecnologia da informação, busca assegurar a transparência e confiabilidade dos dados divulgados. Percebe-se que os controles visam assegurar a ética das organizações.

Conforme a percepção do Gestor $\mathrm{C}$, existe uma relação entre a implementação dessas práticas e a competitividade internacional. Segundo ele, um trabalho procedimentado, controlado e transparente traz maior confiabilidade à empresa como um todo, fato que é notado por clientes e fornecedores. Como consequência, a empresa se torna mais focada e competitiva, tanto no mercado externo como no interno. Segundo o Gestor C, não houve nenhuma prática que não tenha podido ser implementada.

\section{Gestor D}

O ponto de vista do Gestor D difere dos demais, uma vez que este não atua em empresa que possui práticas de GC implementadas, embora seja oriundo de um grupo internacional e exportador. Da mesma forma que os demais entrevistados, o Gestor D mencionou a dificuldade de mudança de cultura e forma de trabalho. O entrevistado afirmou que, se a alta gestão da empresa não estiver comprometida com a adoção das práticas e não sensibilizar os demais colaboradores sobre a importância das mesmas, dificilmente o processo terá sucesso, uma vez que ele depende da conscientização de vários atores.

O Gestor D percebe a governança corporativa como um indicador da maior profissionalização das empresas que as adotam. Ele cita essas práticas como um aprimoramento da gestão. Embora a governança corporativa não seja fator isolado para perpetuação em outros mercados, o entrevistado enxerga a governança como fator adicional à competitividade externa. Ele atribui a fatores intrínsecos ao produto o sucesso no mercado internacional e afirma que dificilmente os clientes irão atribuir maior valor a um produto por conta da adoção de práticas de governança corporativa. No entanto, embora dificilmente os clientes finais percebam a governança 
corporativa como fator diferencial, o Gestor D comenta que, devido a exigências globais, empresas de grande porte que já atendem a normas de GC valorizam stakeholders que já estejam acompanhando esse movimento de readequação de normas de gestão.

Como benefícios, o Gestor D vê que as empresas que atendem a boas práticas de GC têm um fortalecimento de sua imagem no mercado, bem como um aprimoramento em seus processos de gestão. Ele também cita que os colaboradores percebem positivamente as práticas de GC e tendem a ser mais comprometidos à medida que elas são internalizadas.

\subsection{Síntese dos resultados}

A Figura 3resume os resultados das entrevistas e permite uma melhor comparação entre os principais pontos relacionados com as dificuldades e benefícios percebidos no processo de internalização de práticas de governança corporativa.

Figura 3 - Dificuldades e benefícios percebidos

\begin{tabular}{|l|c|c|c|c|c|}
\hline Dificuldades & Gestor A & Gestor B & Gestor C & Gestor D & Soma \\
\hline Mudança de mentalidade & $\mathrm{X}$ & $\mathrm{X}$ & $\mathrm{X}$ & & 3 \\
\hline Conflitos de interesse & $\mathrm{X}$ & & & & 1 \\
\hline Mudança na forma de trabalho & $\mathrm{X}$ & $\mathrm{X}$ & $\mathrm{X}$ & $\mathrm{X}$ & 4 \\
\hline Dificuldades com serviços de TI & $\mathrm{X}$ & $\mathrm{X}$ & $\mathrm{X}$ & & 3 \\
\hline Soma & 4 & 3 & 3 & 1 & 11 \\
\hline Benefícios & Gestor A & Gestor B & Gestor C & Gestor D & Soma \\
\hline Atribuições melhor delineadas & $\mathrm{X}$ & & $\mathrm{X}$ & $\mathrm{X}$ & 3 \\
\hline Segurança aos gestores & $\mathrm{X}$ & $\mathrm{X}$ & & & 2 \\
\hline Atração de novos investidores & $\mathrm{X}$ & & $\mathrm{X}$ & & 2 \\
\hline Informaçõestransparentes e confiáveis & $\mathrm{X}$ & $\mathrm{X}$ & $\mathrm{X}$ & & 3 \\
\hline Profissionalização da empresa & & & & $\mathrm{X}$ & 1 \\
\hline Fortalecimento da gestão & & & & $\mathrm{X}$ & 1 \\
\hline Soma & 4 & 2 & 3 & 3 & 12 \\
\hline
\end{tabular}

Fonte: Elaborada pelos autores com base nos resultados das entrevistas

Percebe-se na Figura 3 que as dificuldades mais citadas foram a mudança na forma de trabalho, a mudança de mentalidade e as dificuldades com serviços de TI. Quanto aos benefícios, os mais citados foram às atribuições melhor delineadas e as informações transparentes e confiáveis.

O entrevistado A foi o que citou o maior número de fatores (oito), seguido pelo entrevistado C, com seis fatores (3+3). O entrevistado B teve uma maior percepção de dificuldades (3) do que benefícios (2), enquanto o entrevistado D citou três benefícios e apenas uma dificuldade.

Quanto à percepção dos gestores sobre a governança corporativa como fator de competitividade global, os resultados encontrados podem ser analisados sob três aspectos: i) 
competitividade pela ótica dos clientes; ii) competitividade na relação entre organizações; e iii) competitividade no mercado de capitais. A Figura 4apresenta os pontos de concordância e divergência dos gestores com relação à governança corporativa como elemento de competitividade em mercados externos.

Figura 4 - Governança corporativa como elemento de competitividade global

\begin{tabular}{|l|c|c|c|c|c|}
\hline Aspecto/ ótica & Gestor A & Gestor B & Gestor C & Gestor D & Soma \\
\hline Clientes & & & $\mathrm{X}$ & & 1 \\
\hline Relação entre organizações & & & $\mathrm{X}$ & $\mathrm{X}$ & 2 \\
\hline Mercado de capitais & $\mathrm{X}$ & $\mathrm{X}$ & $\mathrm{X}$ & $\mathrm{X}$ & 4 \\
\hline Soma & 1 & 1 & 3 & 2 & 7 \\
\hline
\end{tabular}

Fonte: Elaborada pelos autores com base nos resultados apurados

No que diz respeito à competitividade das empresas no mercado de capitais e à atração de investidores, os entrevistados foram unânimes: todos os gestores entrevistados afirmaram que as práticas de governança corporativa trazem a confiabilidade e transparência que o mercado valoriza. A robustez que a adequação às práticas de GC proporciona às empresas as difere positivamente no mercado de capitais. Conforme citado na literatura, empresas que aderem às práticas de GC tendem a ter suas ações valorizadas. Percebe-se, portanto, a conscientização dos gestores quanto à importância do tema.

Com relação à competitividade na relação com o cliente, a opinião dos gestores difere. $\mathrm{O}$ Gestor C argumenta que as empresas que estão adequadas às normas de GC tendem a ser mais focadas e, por consequência, mais competitivas, mesmo na relação com clientes. Por outro lado, os gestores A, B e D não percebem a governança corporativa como fator relevante de competitividade em processos que envolvam os clientes.

\section{Conclusões}

Os resultados da pesquisa evidenciam a importância dos aspectos comportamentais da governança corporativa. Conforme trabalhos como o de Steinberg (2003), que explicam que a GC está relacionada com a atitude e escala dos valores humanos, todos os entrevistados citaram a quebra de paradigmas como um dos maiores percalços a serem superados. Este é o ponto convergente das entrevistas que se relaciona com outro aspecto citado na literatura, que afirma que é necessário um esforço coletivo para a construção e consolidação de uma imagem de empresa que pratica GC (RIBEIROet al., 2010).

Em última análise, pode-se dizer que a perpetuação de uma empresa nos mercados externos depende do aprimoramento de sua gestão e adequação a normas reconhecidas internacionalmente, conforme a OCDE (2003). Existe concordância entre essa definição e a opinião dos gestores que 
afirmam que a adoção de práticas de governança corporativa é um diferencial no mercado de capitais, na atração de investidores e no crescimento das companhias.

Um ponto a ser ressaltado é que as entrevistas limitaram-se aos gerentes das áreas de maior interesse para a pesquisa. Fatores como captação de capital a menor custo, por exemplo, não foram citados, o que possivelmente aconteceria caso as entrevistas fossem realizadas com diretores ou agentes da mais alta gestão. A pesquisa capturou a percepção de gestores que atuam em um nível tático, pois são eles que mais têm contato com as mudanças de trabalho exigidas pela internalização de práticas de governança corporativa.

De acordo com os resultados obtidos nesta pesquisa, fica evidente que a questão comportamental do tema deve ser avaliada de forma cuidadosa no momento da implementação de práticas de governança corporativa. A pesquisa mostra que processos dessa magnitude exigem um preparo dos agentes envolvidos, uma vez que eles podem influenciar a forma como as práticas serão internalizadas.

\section{Abstract}

The objective of this studywas to analyze the perception of exporting companiesmanagers of Caxias do Sul about corporate governance as a factor of global competitiveness. The approach used for the investigation was qualitative and exploratory. Data were collected through semi-structured questionnaire and analyzed highlighting the main benefits and difficulties of corporate governance practices implementation in the studied companies as well as the impact of governance practices in global competitiveness. The results indicate that managers realize the importance of adopting practices to perpetuate organizations in the capital market, although this aspect is not considered important in the relationship with the customers. According to the literature, this research also revealed the importance of behavioral aspects associated to the governance, such as a mindset changing, breaking paradigms and culture shock.

Keywords: corporate governance; global competitiveness; perception of managers; exporting companies; caxias do sul.

\section{Referências}

ANDRADE, A; ROSSETTI, J. P. Governança corporativa: fundamentos, desenvolvimento e tendências. São Paulo: Atlas, 2004.

BABIC, V. Corporate governance problems in transition economies. Winston-Salem: Wake Forest University, Social Science Research Seminar, 2003.

BARDIN, L. Análise de conteúdo. Lisboa: Edições 70, 2000.

BARROS, J. R. M. Desafios e oportunidades para o mercado de capitais brasileiro. São Paulo: Bovespa, 2002.

BAUER, M. W.; GASKELl, G. Pesquisa qualitativa com texto, imagem e som: um manual prático. Petrópolis: Vozes, 2002.

BERLE, Adolf A.; MEANS, Gardiner C. A moderna sociedade anônima e a propriedade privada. São Paulo: Abril Cultural, 1984. 
BLAIR, M. M. For whom should corporations be run?An economic rationale for stakeholder management.Long Range Planning, v. 31, n. 2, p. 195-200, 1999. crossref

FIGUEIREDO, N. M. A. Método e metodologia na pesquisa científica. São Paulo: Difusão, 2004.

FRAZÃO, C. Da possibilidade de regulação de agências de rating no Brasil(Monografia). Universidade Federal do Rio de Janeiro, Instiuto de Economia, 2005.

IBGC - Instituto Brasileiro de Governança Corporativa. Código das Melhores Práticas de Governança Corporativa. 4. ed. São Paulo: IBGC, 2009.

JUSTEN FILHO, M. Comentários à lei de licitações e contratos administrativos. 12.ed. São Paulo: Dialética, 2008.

LEMES, S.; SANTOS, L. A. A. A Lei Sarbanes-Oxley: uma tentativa de recuperar a credibilidade do mercado de capitais norte-americano. I congresso USP de Iniciação Científica em Contabilidade. São Paulo, 2004.

MCKINSEY \& COMPANY, KORN/FERRY INTERNATIONAL. Panorama de Governança Corporativa no Brasil.São Paulo, 2001

MCKINSEY \& COMPANY. Investor Opinion Survey on Corporate Governance.London: June, 2000.

MONKS, R.; MINOW, N. Corporate Governance.3.ed.Oxford: Blackwell,1995.

OECD.Guidelines for multinational enterprises: annual report 2001. Global instruments for corporateresponsability. Paris: OECD, 2001.

OECD. White paper on Corporate Governance in Latin America. Paris: OECD, 2003

PETERS, M. R. S. Implantando e gerenciando a Lei SarbanesOxley: governança corporativa agregando valor aos negócios. São Paulo: Saraiva, 2007.

PORTER, M. E. Estratégia competitiva: técnicas para análise de indústrias e da concorrência. 28.ed. Rio de Janeiro: Campus, 2003.

RIBEIRO, H. C.; MURITIBA, P. M.; MURITIBA S. N.; BUCHERONI, C. A. Reflexões sobre o aspecto humano na Governança Corporativa. In: XII Seminários em administração- SEMEAD. São Paulo, 2010..

ROGERS, P. Governança corporativa, mercado de capitais e crescimento econômico no Brasil. Dissertação (Mestrado). Universidade Federal de Uberlândia, Faculdade de gestão de negócios, 2006.

SANDES, L.A. Governança Corporativa tem resultado traduzido pelo mercado. São Paulo, 2010. Disponível em:<http://www.bmfbovespa.com.br/juridico/noticias-e-entrevistas/Noticias/Governanca-corporativa-tem-resultadotraduzido-pelo-mercado.asp> Acesso em: 22 de out. 2012.

SILVEIRA, A. M. Governança Corporativa, Desempenho e Valor da Empresa. São Paulo: FEA/USP, 2002 (Dissertação de Mestrado).

STEINBERG, Herbert. A dimensão humana da governança corporativa: pessoas criam as melhores e as piores práticas. São Paulo: Gente, 2003.

VIEIRA, E. R.; CORRÊA, V. P. Mercado de Capitais e Governança Corporativa no Brasil: reflexões sobre os movimentos recentes. VII Encontro Regional de Economia, Fortaleza, Fórum Banco do Nordeste de Desenvolvimento,2002.

WILLIAMSON, O. E. The mechanisms of governance. New York: Oxford University Press, 1996. 


\section{Dados dos autores:}

\section{Nome completo: Camila Ploia Haas Manera}

Filiação institucional: Autarquia Municipal de Turismo Gramadotur

Departamento: Compras

Função ou cargo ocupado: Gerente de Compras e Almoxarifado

Endereço completo para correspondência: Rua Augusto Bordin, 305 - B. Floresta - Gramado - RS CEP 95.670-000

Telefones para contato: (54) 8126-1699

e-mail:ploiahaas@gmail.com

Nome completo: Guilherme Bergmann Borges Vieira

Filiação institucional: Universidade de Caxias do Sul

Departamento: Centro de Ciências Sociais (CCSO)

Função ou cargo ocupado: Professor adjunto

Endereço completo para correspondência: Rua Francisco Getúlio Vargas, 1130 - Bairro Petrópolis Caxias do Sul - RS - CEP 95070-560

Telefones para contato: (54) 3218-2100

e-mail: gbbvieir@ucs.br

Submetido em: 07-01-2016

Aceito em: 15-06-2016 